\title{
AN EXPLORATORY STUDY ON DETERMINING FACTORS FOR THE SMARTPHONE SELECTION DECISION
}

\author{
Dalsang Chung, Governor State University, dchung@govst.edu \\ Sun Gi Chun, Alabama State University, sungichuhn@alasu.edu
}

\begin{abstract}
Mobile technology continues to shape how individuals communicate, whether in a business or individual settings. Smartphones allow people to communicate and do things that have traditionally been done by computers or laptops, hence gradually reducing the need for said computers or laptops. However, selecting a smartphone device that fits users' needs is not an easy task given the competition among diverse products available on the market. The focus of this study is to extend the Technology Acceptance Model (TAM) to explorer determining factors of smartphone selection decision that include the user's perception of usefulness, ease of use, available applications, application updates, opinion of social peer group, and security/privacy. Online survey on the selection factors was conducted to smartphone consumers. Survey results support that new smartphone users mostly select particular devices based upon ease of use, usefulness, and application updates.
\end{abstract}

Keywords: Smartphone, Smartphone Selection, Decision Factors

\section{INTRODUCTION}

Smartphone usage has been on the rise so that it has gradually replaced traditional cell phones and personal digital assistants (PDA). According to Admob February 2010 Mobile Metrics Report, smartphones accounted for 48 percent of wireless traffic, up from 35 percent of the year before. In absolute terms, it was contended that traffic increased a full 193 percent from February 2009 [2]. Despite this growth, earlier studies have not been able to address entirely the factors smartphone consumers consider in adopting and using smartphones. The wireless device chosen by new smartphone consumers is predicated by multiple factors. The discerning factors include both usability and functionality as well as the preference of the social peers. We opine that people select the device based on both personal evaluations as well as the group opinions on smartphones. This social influence group is reduced as users develop expertise in the various technology platform, capabilities, and quirks.

The objective of the study is to examine determining factors for smartphone brand selection decision by consumers. In order to collect data, the authors conducted an online survey to consumers. The survey results would provide valuable insights for smartphone marketers selling/promoting smartphones as well as technology innovators developing smartphone applications that attract potential consumers.

\section{LITERATURE REVIEW}

Technology Acceptance Model (TAM) and Diffusion of Innovation (DOI) theories have proven to be a useful theoretical framework for understanding user acceptance and behaviour related to information technologies. Davis $[3,4]$ developed the TAM (See Figure 1) and investigated the determinants of user acceptance that can explain a user's behaviour in regard to the user's general attitude toward the selection of an information system. According to the TAM, users evaluate the system based on the perceived ease of use and perceived usefulness of the system. If the system is perceived as being easy to use and useful, a user would have a positive attitude toward the system, which in turn leads to the user's intention to use the system. Then, the intention results in the user's actual decision to select a particular information technology which in this case is the smartphone. Among subsequent studies testing the model, most notable is Kim's study, "Moderating Effects of Job Relevance and Experience on Mobile Wireless Technology acceptance: Adoption of a smartphone by individuals [8]." The data supports the notion that the model is valid, but too simple, given that significant variance is not accounted for. 


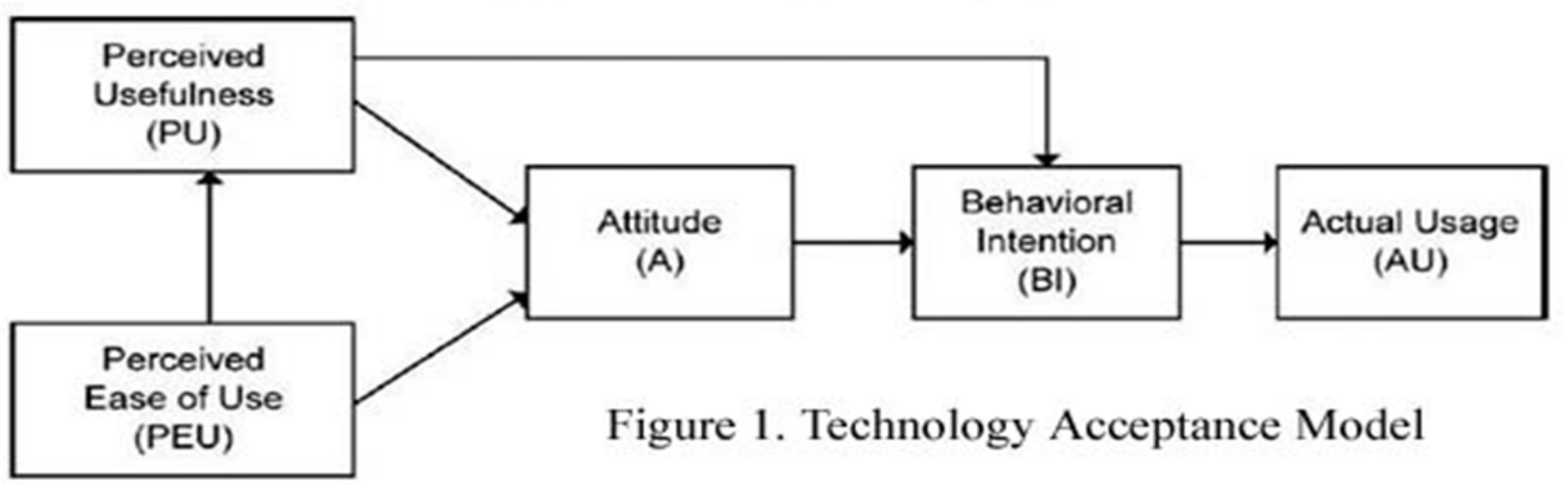

Independently, a research study conducted by Park and Chen [9] confirmed that behavioural intention to use a smartphone was largely influenced by perceived usefulness and attitude toward using a smartphone. They further postulated that perceived usefulness (PU) and perceived ease of use (PEU) positively determine attitudes toward using a smart phone. This is consistent with the Davis’ TAM model.

According to Rogers [11], DOI Theory is concerned with the manner in which a new technological idea, artifact or technique, or a new use of an old one, migrates from creation to use. The smartphone was first introduced to the market in the year 2000. Thus, we view smartphone devices as recent innovations and employ the Rogers' DOI theory to evaluate whether an individual or an organization will select a smartphone based on their knowledge on its functionality and usability. This is consistent with the Davis' TAM model when we substitute usefulness for functionality and ease of use for usability.

Kim [8] extended TAM (See Figure 2) to show how perceived ease of use and usefulness influence users' attitude towards smartphone adoption in a job setting by adding the following factors: perceived cost savings (PCS), job relevance (JR), company's willingness to fund (CWF), and experience (E). These factors were applied in an online survey and were tested against the proposed model using Structured Equation Modelling (SEM). The results from 286 sets of data supported the new model, and raised the percentage of the variance of the model to $62.7 \%$ from approximately 50\% from the Davis' TAM model although there was an increase in the variance of two of the added factors that accounted for about 5\%. The model was able to better predict results than its predecessor. Accordingly, it is clear that although Kim's expansion of the Davis' TAM model is more sophisticated, and represents a better model, the Kim's expanded TAM model still has not identified all factors to be considered. 


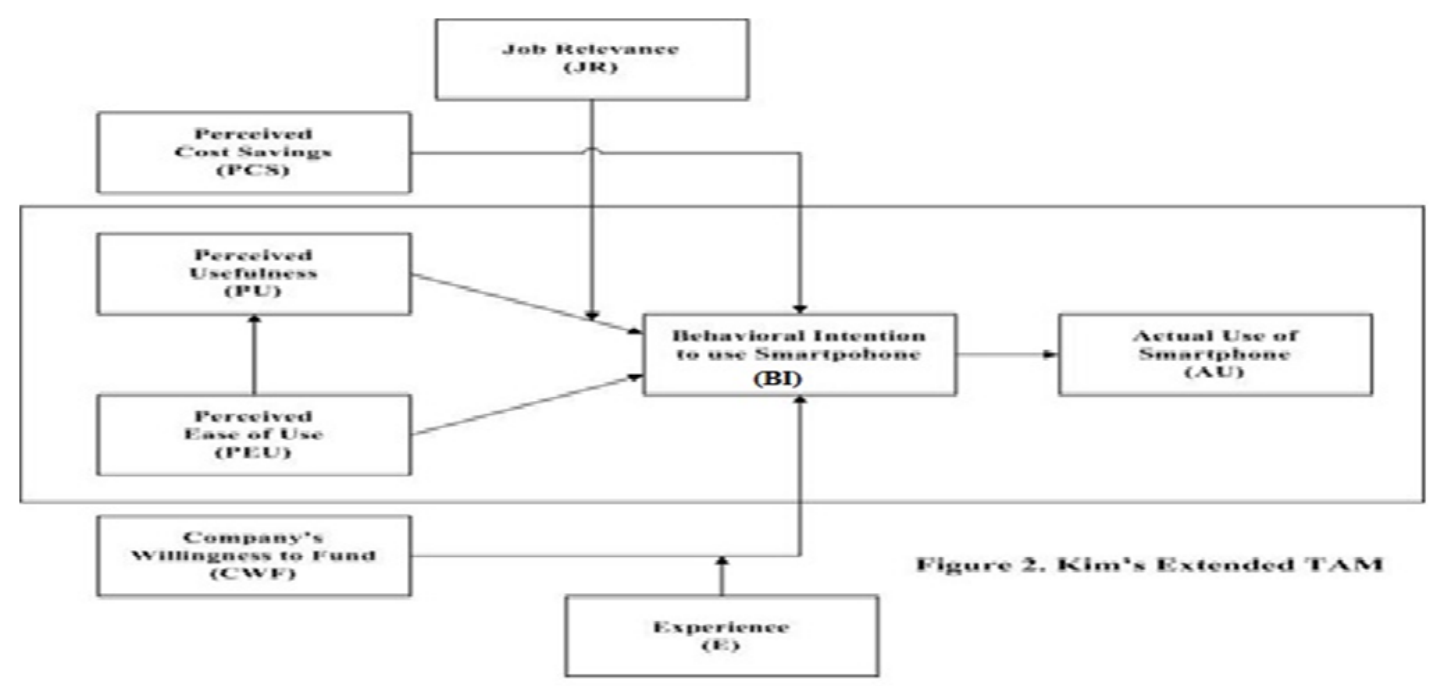

In contrast, our research focuses on the individual consumer, not necessarily adopting technology in the workplace. We build a model (See Figure 3) based upon the Kim's expanded TAM model and DOI to explain the factors that influence an individual in adopting a smartphone. As a result, the following factors are considered: perceived applications update (PAU), perceived available applications (PAA), perceived smartphone company's willingness to update operating system (POS), influence of the social network (SN), and security/privacy (SP).

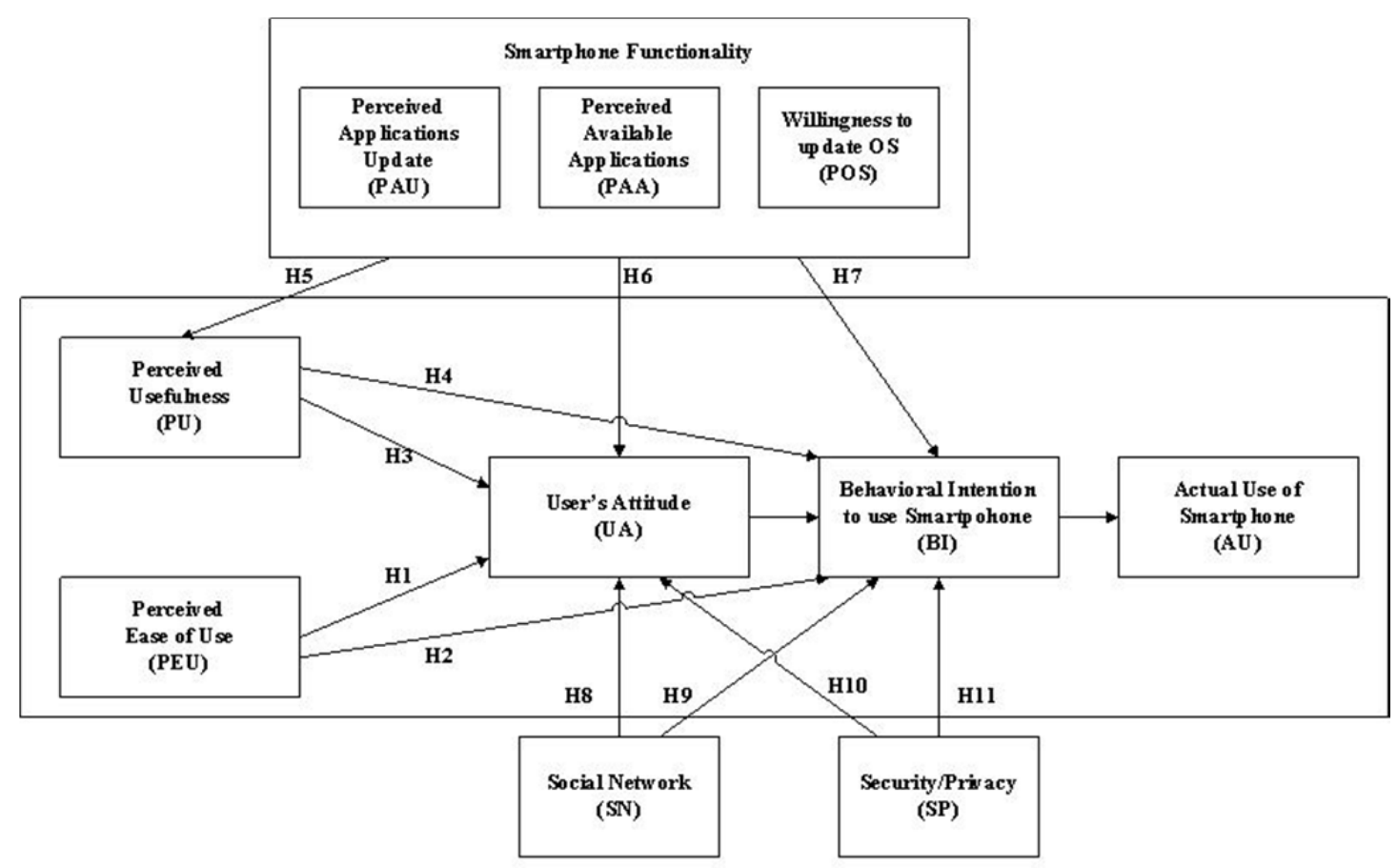

Figure 3. Research Model 


\section{Issues in Information Systems}

Volume XII, No. 1, pp. 291-300, 2011

\section{HYPOTHESES}

Our research model for smartphone selection factors considers users' attitude towards particular brands and technology platforms, whether iPhone, Blackberry, Android, or others. We hypothesize that perceived usefulness (PU) is positively affected by perceived applications update (PAU), perceived available applications (PAA), and perceived smartphone company's willingness to update operating system (POS). Engle and Blackwell [5] support this belief, stating that customers' satisfaction comes from an evaluation of the chosen alternative being consistent with prior beliefs, which is perceived as being useful.

Moreover, it is believed that there is a positive effect of the social network (SN) and security/privacy (SP) on behavioural intention (BI). The influence of social networks on the adoption decision has also led to the emergence of another theory, namely, Social Influence Network Theory (SINT). SINT is a combination of social network theory and social diffusion theory. According to Johnsen and Friedkin [7], social diffusion is a process by which particular thoughts (attitudes, opinions, or beliefs), feelings (emotions, sentiments, or moods), or behaviours (decisions, actions, or practices) are spread among members of a social network. This theory suggests that for smartphone adoption, users are more likely to select the smartphone that is most popular within the particular social network. However, it is expected that this causal relationship will diminish as the user develops experience with various smartphone platforms and accordingly is able to critically evaluate core competencies of the device based on user's core requirements being independent of the social network. Finally, it is further expected that this causal relationship will diminish as the user's age increases.

Security is one of the factors determining smartphones. Smartphones are used to store comprehensive contact list, regularly log in social network, and contain a list of passwords. According to Consumer reports [1], 9\% mobile phone owners, mostly smartphone owners, used their phone for banking. Losing a phone and being infected by malicious software are two main risk factors in terms of security. The easiest way to protect personal data from the loss of smartphones is to set up a personal identification number or password on the phone. On an Apple iPhone, there is a choice for setting a passcode while on Android smartphones, there is a location and security option. In order to protect personal data from the attack of malware, smartphone users are to regularly download software update and back up data to another device. Smartphone makers or commercial software called Lookout offer free security services such as over the air backup, remote phone locating, remote phone locking, and erasing data and account information. Recently, a malware called DroidDream has infected about 260,000 Android phones [1]. Victims downloaded the malware from Google's Android Market on more than 50 apps designed to imitate popular applications, which was quickly cleared by Google. However, malware targeting smartphones has been fast increasing. iPhone users can securely download apps from the relatively more secured Apple's app store than Android smartphone users.

Another security/privacy issue is on GPS tracking features of smartphones. According to Consumer Report [1], more than 8 million people in the world use Foursquare, a social network app that let users comment about restaurants, and stores with incentives of discounts and free gifts. However, the service can let friends and strangers on social networking sites know locations of the users. Moreover, photos taken with smartphones also present a similar security/privacy risk when users post geotagged photos to photo sharing service sites such as Flickr. Therefore, smartphone users want to select smartphones that are easy to turn off GPS features and not to allow to share the location when they post photos to social networking sites.

Carrier service coverage is also potentially a driving factor for smartphone selection. For instance, Apple had had an exclusive contract with AT\&T for the usage of iPhone until Verizon made a contract recently with Apple so that some prospective users might want an iPhone, but not the AT\&T service because the user might perceive AT\&T's quality of service to be insufficient to their needs. In other cases, users may be willing to switch to the AT\&T service network because of the iPhone's exclusive availability on the network.

In spite of not being tested in this study, personal demographics also potentially play a role in the selection decision such as the consumer's age, gender, and other personal experience traits. Personal experience includes factors such as the consumer's computer background, education, and literacy. Previous literature shows a positive relationship between personal demographics and personal experience with innovation adoption [6]. 


\section{Issues in Information Systems}

Volume XII, No. 1, pp. 291-300, 2011

From the above discussion about the smartphone selection decision, followings are hypothesized:

H 1: Perceived ease of use (PEU) of the smartphone has a direct effect on the user's attitude (UA).

H2: Perceived ease of use (PEU) of the smartphone has a direct effect on behavioural intention (BI).

H3: Perceived usefulness (PU) of the smartphone has a direct effect on the user's attitude (UA).

H4: Perceived usefulness (PU) of the smartphone has a direct effect on behavioural intention (BI).

H5: Functionality of smartphone (PAU, PAA, POS) has a direct effect on perceived usefulness (PU).

H6: Functionality of smartphone (PAU, PAA, POS) has a direct effect on the user's attitude (UA).

H7: Functionality of smartphone (PAU, PAA, POS)has a direct effect on behavioural intention (BI).

H8: Social peer's influence (SN) has a direct effect on the user's attitude (UA).

H9: Social peer's influence (SN) has a direct effect on behavioural intention to use the smartphone (BI).

H10: The user's security/privacy concern (SP) has a direct effect on the user's attitude (UA).

H11: The user's security/privacy concern (SP) has a direct effect on behavioural intention to use the smartphone (BI).

\section{REARCH METHODOLOGY}

The survey instrument was designed to have twenty-four (24) items to measure nine (7) major factors, perceived ease of use (PEU), perceived usefulness (PU), the user's attitude (UA), behavioural intention (BI), three aspects of functionality of smartphone (PAU, PAA, POS), social peer's influence (SN), and the user's security/privacy concern (SP). Questions on demographics of subjects were included in the survey such as age, gender, and education. Twenty-two (22) items to measure consumers' perception of the major factors were statements for respondents to reply on a 5 point Likert scale, that is, one (1) for strongly disagree and five (5) for strongly agree. Two (2) items were designed separately to examine social peer's influence by five (5) degrees of social conformity in terms of smartphone devices and wireless carriers, (1) for none and (5) for most.

The target population for the survey was smartphone users who purchased a smartphone between January, 2009 and August, 2010. Individual respondents were solicited through a survey. Data was collected by means of an online survey through Survey Monkey, a web survey service provider. The survey was conducted over four week period. The survey was emailed to respondents with a link to the Survey Monkey website. The follow up e-mail was sent out to remind to complete the online survey. To recruit more participants, we encourage each participant to spread the survey existence and survey link through their e-mail or social network sites. The rationale for online survey data collection was that it was cheaper and less time consuming because many smartphone users have browsing capability. In addition, online survey allows respondents to answer at the leisure rather than often at the inconvenient time for responding to survey questions. However, there were some weaknesses associated with online survey; for instance, users might consider the survey email as a junk mail.

Variables involved in this survey were smartphone selection decision as a dependent variable, and usability and functionality as independent variables. Multivariate analysis of variance tests were employed to test hypotheses we defined. The variables for perceived ease of use, perceived usefulness, perceived social peer influence, perceived functionality of the smartphone, and privacy/security concern are independent variables along with dependent variables, behavioral intention and attitude, applied respectively to each hypothesis. 
Volume XII, No. 1, pp. 291-300, 2011

\section{DATA ANALYSIS AND DISCUSSION}

The demographics of respondents are shown in the Table 1.

Table 1: Demographic Results

\begin{tabular}{|l|l|l|}
\hline Demographic Categories & Frequency & Percentage - \% \\
\hline & & \\
\hline Age (years) & & \\
\hline $18-25$ & 12 & $7.59 \%$ \\
\hline $26-32$ & 26 & $16.46 \%$ \\
\hline $33-44$ & 73 & $46.20 \%$ \\
\hline $45-60$ & 43 & $27.22 \%$ \\
\hline $61+$ & 4 & $2.53 \%$ \\
\hline & & \\
\hline Gender & & \\
\hline Male & 101 & $64.74 \%$ \\
\hline Female & 55 & $35.26 \%$ \\
\hline & & \\
\hline Education & & \\
\hline High School & 0 & $0.00 \%$ \\
\hline Technical / Trades & 0 & $3.16 \%$ \\
\hline Some College & 5 & $12.66 \%$ \\
\hline Bachelor's Degree & 20 & $35.44 \%$ \\
\hline Graduate or Higher & 56 & $48.73 \%$ \\
\hline
\end{tabular}

Out of 160 respondents, almost a half of respondents were in the age of 33 through 44 and age group of 18 through 25 were only $7.6 \%$. In terms of gender, $65 \%$ of respondents were male while $35 \%$ were female. In terms of education, $84 \%$ of respondents were at least college graduates.

Table 2 shows descriptive statistics on the question items. One thing to note is that social peer's opinion on smartphone devices does not influence on consumers while social peer's opinion on wireless carriers influences more on consumers. 


\section{2: Survey Question Results}

\begin{tabular}{|c|c|c|c|}
\hline Survey Question & Variable & Mean & Std Dev \\
\hline $\begin{array}{l}\text { Using a smartphone in my job would enable me to accomplish tasks more } \\
\text { quickly }\end{array}$ & F1 & 4.03 & 0.842 \\
\hline Using a smartphone in my job would increase my productivity & F2 & 3.84 & 0.951 \\
\hline I would find a smartphone useful in my job & F3 & 4.29 & 0.790 \\
\hline Using a smartphone would improve my job performance & F4 & 3.66 & 0.876 \\
\hline Using a smartphone would enhance my effectiveness on the job & F5 & 3.78 & 0.876 \\
\hline I would find it easy to get a smartphone to do what I want to do & F6 & 3.87 & 0.817 \\
\hline I would find a smartphone easy to use. & F7 & 3.98 & 0.828 \\
\hline Learning to operate a smartphone would be easy for me & F8 & 4.07 & 0.862 \\
\hline My interaction with a smartphone would be clear and understandable & F9 & 3.92 & 0.816 \\
\hline Assuming I have access to a smartphone, I intend to use it & F10 & 4.27 & 0.783 \\
\hline Given that I have access to a smartphone, I predict that I would use it & F11 & 4.23 & 0.763 \\
\hline Using the smartphone for working is (would be) a good idea. & F12 & 4.07 & 0.770 \\
\hline Using the smartphone while working is unpleasant. & F13 & 1.86 & 0.865 \\
\hline Using the smartphone is beneficial to my work. & F14 & 4.11 & 0.832 \\
\hline I like (would like) using the smartphone for working. & F15 & 4.19 & 0.843 \\
\hline How many of your peers owned/used the same device you selected? & F16 & 2.91 & 1.200 \\
\hline How many of your Peers used the same wireless carrier you selected? & F17 & 3.25 & 1.082 \\
\hline $\begin{array}{l}\text { You chose your smartphone because of a recommendation from your social } \\
\text { Peers. }\end{array}$ & F18 & 1.96 & 1.087 \\
\hline $\begin{array}{l}\text { You chose your wireless carrier because of a recommendation from your social } \\
\text { Peers. }\end{array}$ & F19 & 1.78 & 1.085 \\
\hline I would consider available Apps(applications) in selection of the smartphone & F20 & 3.66 & 0.925 \\
\hline $\begin{array}{l}\text { I would consider how well Apps(applications) would be updated in selection of } \\
\text { the smartphone }\end{array}$ & F21 & 3.39 & 0.877 \\
\hline $\begin{array}{l}\text { I would consider how well OS(Operating Systems) would be updated in } \\
\text { selection of the smartphone }\end{array}$ & F22 & 3.51 & 0.958 \\
\hline $\begin{array}{l}\text { I am concerned } t \text { the incidents of security breach from smartphone occurred } \\
\text { recently. }\end{array}$ & F23 & 3.14 & 1.119 \\
\hline $\begin{array}{l}\text { I am concerned my personal information from the smartphone might be exposed } \\
\text { to the public. }\end{array}$ & F24 & 3.09 & 1.109 \\
\hline
\end{tabular}

Table 3 presents the VARIMAX rotated factor matrix identifying the seven (7) factors by items. According to this matrix, seven factors can be labeled as perceived usefulness (PU), perceived ease of use (PEU), behavioral intention (BI), social peer influence (SI), perceived apps availability (PAA), and security/privacy(SP) while one (1) factor, the user's attitude (UA) was not grouped as a factor. Also, social peer's influence (SN) factor was counted as two in the factor analysis because of the two different question scales. After factors were identified, the reliability of factors in the instrument was also examined. Internal consistency for the measure were demonstrated by Cronbach's alpha values for the seven factors (.8725, .8299, 8199, .8285, .7315, .7025 and .7590). 


\section{Issues in Information Systems}

Volume XII, No. 1, pp. 291-300, 2011

Table 3: Factor Loading of Factor Analysis

\begin{tabular}{|rrrrrrrr|}
\hline & Factor1 & Factor2 & Factor3 & Factor4 & Factor5 & Factor6 & Factor7 \\
\hline & & & & & & & \\
\hline F1 & $\mathbf{0 . 7 4 1 8 0}$ & 0.21739 & 0.10250 & 0.33874 & -0.07080 & 0.16403 & -0.05583 \\
\hline F2 & $\mathbf{0 . 8 3 6 1 5}$ & 0.14133 & 0.16342 & 0.10346 & -0.02609 & 0.12233 & 0.10589 \\
\hline F3 & $\mathbf{0 . 5 8 0 4 8}$ & 0.30495 & 0.08935 & 0.45862 & 0.01012 & 0.18216 & -0.08073 \\
\hline F4 & $\mathbf{0 . 8 3 8 1 7}$ & 0.17340 & 0.15748 & 0.04521 & 0.06668 & 0.01406 & 0.16278 \\
\hline F5 & $\mathbf{0 . 8 2 4 3 7}$ & 0.16911 & 0.16609 & 0.06808 & 0.04439 & 0.10393 & 0.11820 \\
\hline F6 & 0.21967 & $\mathbf{0 . 8 1 8 3 4}$ & 0.12917 & 0.07958 & 0.02713 & 0.05440 & 0.03026 \\
\hline F7 & 0.18935 & $\mathbf{0 . 8 8 4 3 7}$ & 0.17036 & 0.13103 & 0.07080 & 0.07701 & 0.05007 \\
\hline F8 & 0.17049 & $\mathbf{0 . 7 5 7 3 8}$ & 0.22761 & 0.14045 & 0.07657 & 0.10177 & 0.08380 \\
\hline F9 & 0.19300 & $\mathbf{0 . 6 9 5 4 2}$ & 0.30918 & 0.14075 & 0.08085 & 0.04323 & 0.06124 \\
\hline F10 & 0.42173 & 0.39782 & 0.10120 & $\mathbf{0 . 6 8 4 6 4}$ & 0.05783 & 0.08242 & 0.07647 \\
\hline F11 & 0.37690 & 0.34872 & 0.16010 & $\mathbf{0 . 6 7 5 2 0}$ & 0.09932 & 0.01273 & 0.10176 \\
\hline F12 & 0.60397 & 0.37121 & 0.19916 & 0.29541 & 0.01970 & 0.08638 & 0.00344 \\
\hline F13 & -0.13740 & -0.39376 & 0.06059 & -0.22209 & 0.29230 & -0.10974 & 0.02898 \\
\hline F14 & 0.60756 & 0.46578 & 0.07038 & 0.40322 & -0.12431 & 0.19575 & -0.05484 \\
\hline F15 & 0.39749 & 0.64425 & 0.04484 & 0.39439 & -0.08472 & 0.12566 & -0.10206 \\
\hline F16 & 0.14138 & 0.23055 & -0.02923 & -0.00995 & -0.02321 & $\mathbf{0 . 8 5 0 7 7}$ & 0.10485 \\
\hline F17 & 0.13030 & 0.01211 & 0.05922 & 0.08632 & -0.07461 & $\mathbf{0 . 5 4 8 6 0}$ & 0.09624 \\
\hline F18 & 0.06965 & 0.11197 & -0.06275 & 0.08062 & -0.06494 & 0.29083 & $\mathbf{0 . 5 9 1 1 4}$ \\
\hline F19 & 0.09156 & -0.01513 & 0.00039 & -0.02214 & -0.04886 & 0.00643 & $\mathbf{0 . 7 6 0 5 4}$ \\
\hline F20 & 0.18736 & 0.23048 & $\mathbf{0 . 6 5 1 0 7}$ & 0.12619 & 0.07136 & -0.04121 & 0.04608 \\
\hline F21 & 0.13006 & 0.15696 & $\mathbf{0 . 9 3 6 6 1}$ & -0.03276 & 0.05777 & 0.05673 & -0.02099 \\
\hline F22 & 0.17227 & 0.13193 & $\mathbf{0 . 5 1 1 7 9}$ & 0.08067 & 0.16014 & 0.03349 & -0.08471 \\
\hline F23 & 0.02569 & 0.08616 & 0.16987 & 0.03831 & $\mathbf{0 . 7 7 2 6 6}$ & -0.11137 & 0.01939 \\
\hline F24 & 0.00577 & 0.00439 & 0.06805 & 0.03309 & $\mathbf{0 . 8 5 3 5 3}$ & 0.00634 & -0.14365 \\
\hline & & & & & & & \\
\hline
\end{tabular}

The multivariate analysis was examined to test the relationships between user intention to make a smart phone selection based on Perceived Usefulness, (PU), Perceived Ease of Use (PEU), Perceived Application Updates (PAU), Perceived Applications Available (PAA) and Perceived Operating System Updates (POS), with two moderating effects: Social Network (SN) and Security/Privacy Concerns (SP). As expected, TAM variables were consistent with previous studies. Additionally, a new variable introduced had a significant effect on users' behavioral intentions, which was Perceived Application Updates (PAU). 
Volume XII, No. 1, pp. 291-300, 2011

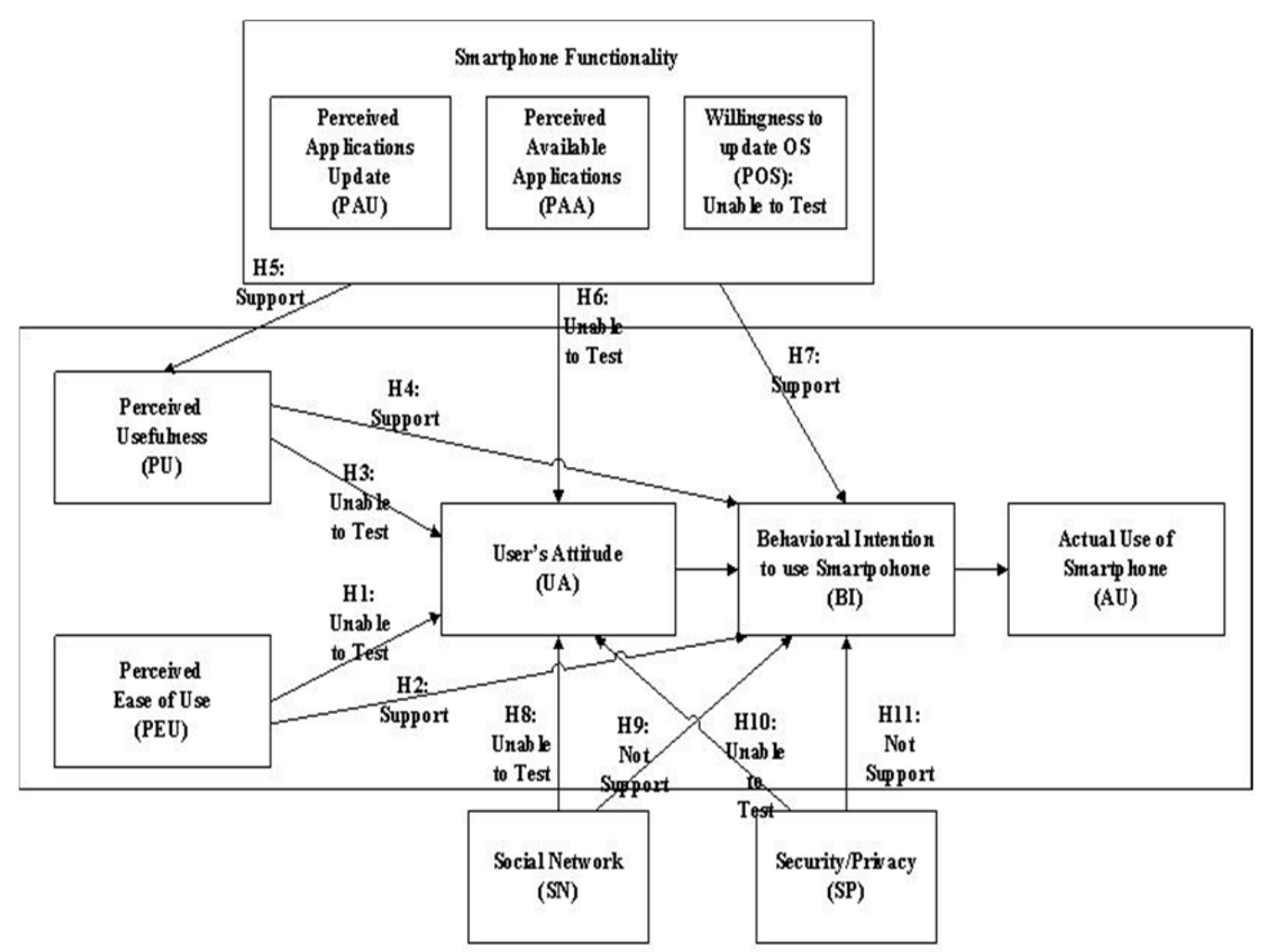

Figure 4. Results of Data Analysis

Figure 4 demonstrated results of testing hypotheses. Before performing ANOVA, and MANOVA analysis, reliability and validity of the data were assessed to ensure the adequacy of data. As a result of factor analysis, the user's attitude (UA) was not counted as a factor so that hypotheses related to UA, that is, H1, H3, H6, H8, and H10, could not be tested. By ANOVA, and MANOVA analysis, firstly, PU was significantly related to an individual's behavioral intention to select a particular type of smartphone (given $\mathrm{df}=18$, ss $=57.69387599 \mathrm{~ms}=3.20521533$, $\mathrm{f}$ value=11.37, $\mathrm{p}<0.001$ ). Moreover, PEU had a significant impact on BI (given $\mathrm{df}=16$, ss=49.33920383 $\mathrm{ms}=3.08370024$, f-value=9.17, $\mathrm{p}<0.001$ ). BI was significantly related to PAU of a smartphone (given $\mathrm{df}=12$, $\mathrm{ss}=15.33415598 \mathrm{~ms}=1.27784633$, f-value=2.29, $\mathrm{p}<0.0107$ ). Thus, PU and PEU were supported. Secondly, there was no support for SI. The study indicated that social peer influence did not affect the smartphone selection. With respect to the impact of the functionality of smartphone (PAA, PAU, POS) on the perceived usefulness (PU), the test showed that the functionality of the smartphone is a significant factor for the perceived usefulness of the smartphone (given $\mathrm{df}=12$, $\mathrm{ss}=18.825841 \mathrm{~ms}=1.568841$, $\mathrm{f}$-value $=2.45, \mathrm{p}<0.0061$ ). H11 on the security/privacy concern for the behavioral intention of the smartphone selection was not supported. Thirdly, respondents agreed that they would select a smartphone that was consistent with application updates and availability. Thus, PAA and PAU were supported (given $\mathrm{df}=12$, ss=15.33415598 ms=1.27784633, $\mathrm{f}$-value=2.29, $\mathrm{p}<0.0107$ ).

\section{CONCLUSION}

Our study examined if perceived application availability (PAA), perceived application update (PAU), social peer's influence (SN), and security and privacy concerns (SP) had relationship with the behavioral intention (BI) in motivating users to select a particular smartphone. The following relationships in the model were found to be significant: perceived usefulness and perceived ease of use continued to have an impact on a user's behavioral intention, which had a significant impact on the selection of a smartphone. Although the results of data analysis did 
not support the hypotheses relating to social peer influence, the results were consistent with the authors' belief that social peer influence is less effective when respondents are in the older generation. In the survey, respondents of 33 years or older represented $75.95 \%$ of the responses.

The moderating effect of PAA/PAU was also found to be significant. The effect of this construct has not been examined in previous studies. In and out of the workplace, individuals are more willing to adopt a smartphone that is useful and easy to use. Overall, in reaffirmation to the TAM model, we found that an individual's intention to select a smartphone was significantly affected by perceived ease of use (PEU) and perceived usefulness (PU). In addition, PAA/PAU is another factor that we found to have a significant impact on the smartphone selection. This study proved that the key element of adopting a smartphone over a feature phone is available applications for users' preference.

The study had several limitations which must be noted. The first one is common to all survey research: a possible self-reporting bias: some of the variables were self-reported. Secondly, it was not expected to find out that some constructs such as the social peer's influence (SN) and security and privacy concerns (SP) were not supported by the research model because of the small sample size or the moderating factors.

\section{REFERECES}

1. Online Exposure. (2011, June). Consumer Reports. 76(6), 29-31.

2. Admob (2010). http://metrics.admob.com/wp-content/uploads/2010/03/AdMob-Mobile-Metrics-Feb-10.pdf

3. Davis, F. D. (1989). Perceived usefulness, perceived ease of use, and user acceptance of information technology. MIS Quarterly, 13(3), 319-339.

4. Davis, F. D., Bagozzi, R. P., \& Warshaw, P. R. (1989). User acceptance of computer technology: A comparison of two theoretical models. Management Science, 35(8), 982-1003.

5. Engel, J. F. \& Blackwell, R. D. (1982). Consumer Behavior. Chicago, IL: The Dryden Press.

6. Harman, K., \& Koohang A. (2006) Diffusion of Selected Concepts in Information Systems and Management. Industrial Management \& Data Systems, 106 (5), 663-679

7. Johnsen, E. C. \& Friedkin, N. E. (2006). Social Influence Network Theory: Diffusion of Attitudes leading to Behavior. Paper presented at the annual meeting of the American Sociological Association, Montreal Convention Center, Montreal, Quebec, Canada Online <PDF $>$. 2009-05-25 from http://www.allacademic.com/meta/p105115_index.html

8. Kim, S. H. (2008). Moderating effects of Job Relevance and Experience on mobile wireless technology acceptance: Adoption of a smartphone by individuals. Information and Management , 45 (6), 387-393.

9. Park, Y., \& Chen. J. V. (2007). Acceptance and Adoption of the Innovative Use of Smartphone. Industrial Management and Data Systems, 107(9), 1349-1365.

10. Ricardo, D. (1817). On the Principles of Political Economy and Taxation. London, UK: John Murray.

11. Rogers, E. M. (1995). Diffusion of Innovations. 4th ed. New York, NY: Free Press. 